\title{
Research on the Relationship Between Chinese Socioeconomic Status (SES), Core Self-evaluation (CSE) and Depression
}

\author{
Yujie Zhang ${ }^{1}$ Simeng Dong, ${ }^{2, *}$, Qinnan Dong ${ }^{3}$

\begin{abstract}
${ }^{1}$ School of Marxism Studies, Chongqing University of Posts and Telecommunications, Chongqing, China
${ }^{2}$ School of Economics and Management, Chongqing University of Posts and Telecommunications, Chongqing, China

${ }^{3}$ Yangtze River Economic Research Center, Chongqing Technology and Business University, Chongqing, China

*Corresponding author. Email: dongsm@cqupt.edu.cn
\end{abstract}

\begin{abstract}
At least 95 million people in China now suffer from depression, and cases of depression and suicide are increasingly common among younger people. This paper aims to study whether CSE is a mediating variable of SES influencing depression and the differences between men and women variables, and then provide practical reference to effectively prevent and relieve the depression. This paper uses the data of CGSS (Chinese General Social Survey) in 2017. Statistical analyses were conducted using SPSS 24.0 and used the PROCESS macro for SPSS (Model 4) to investigate the mediating effect of CSE in the relationship between SES and depression. According to the research results, SES is significantly related to the depression of the Chinese. CSE is a mediating variable between SES and depression and the male and female groups were basically consistent with the total group results.
\end{abstract}

Keywords: Socioeconomic status (SES), Core self-evaluation (CSE), Depression, Chinese General Social Survey (CGSS).

\section{INTRODUCTION}

In recent years, China has seen an unprecedented development in economy. The rapid social reform may result in an increase of psychological pressure and stress level of Chinese as a whole, further bring many mental, cognitive, behavior disorders and the like. The depressive disorder is a common mental disease in the world. According to the Depression and Other Common Mental Disorders issued by WHO in 2017, there were over 350 million people suffering from depressive disorder around the world. In the past 10 years, the number of such patients increased by over $18 \%$ and the morbidity rate in low-income countries and regions was higher than other countries and regions. According to the study of Huang Yueqin et al, the morbidity rate of Chinese patients with lifelong depressive disorder was $6.9 \%$ and the morbidity rate for 12 months was 3.6\%. Therefore, there are at least 95 million patients with depressive disorder in China. As we all know, depression may cause a higher risk of selfmutilation and the intent of suicide ${ }^{[1]}$, and also increase the morbidity of some diseases, for example, neurasthenia, CHD, stroke, etc.
The relationship between SES and psychological health has been attracting wide attentions all the time [2][4]. SES refers to the status of an individual in the social hierarchy of community, including subjective and objective status. Objective socioeconomic status(OSS) reflects the opportunity of an individual getting key social and economic resources, including money, power and social relationship ${ }^{[5]}$. It usually grades the status of an individual in the social hierarchy based on the economic income, level of education, and occupational structure ${ }^{[6]}$. The existing studies have demonstrated that the socioeconomic factors are closely related to the cause of mental disease, and the lower socioeconomic status is related to the worse results of psychological health ${ }^{[7]-[9]}$. According to Cristine et al, those people with lower socioeconomic status were more likely to live in a bad environment and have negative emotions such as sense of loss and depression ${ }^{[10]}$. Therefore, SES has a certain influence on individual depression.

In recent years, many scholars have studied the correlation mechanism between SES and depression and discussed the mediating role of many factors between SES and depression. However, the mediating effect of 
CSE has not been discussed yet. In addition, many factors such as the level of education and gender may also have a close correlation with these variables.

Therefore, this paper creates a mediating model to discuss the mediating role of CSE between SES and depression. In addition, this paper also considers the gender, respectively verifies the mediating effect for the overall samples, male and female samples, analyzes and discusses the difference among these groups.

\section{LITERATURE REVIEW}

As a high-order personal characteristic, CSE has attracted wide attentions in recent years. CSE(Core Selfevaluation) refers to the basic precondition of an individual in evaluating himself and his role in the world ${ }^{[11]}$ and generally includes self-respect, generalized sense of self-efficacy, emotional stability, and control point. According to the research, SES can influence psychological condition of an individual. The higher the SES is, the higher the psychological condition will be. As a determinant of individual major opinions from the society, SES may affect self-respect. Kraus (2012) found from the research system of the USA that the individual with high SES had a better sense of control and tended to, for example, make efforts, but different for the individual with low SES [12]-[15].

In addition, Linville and Patricia(1987)proposed that depressive disorder was related to self-structure. She hypothesized that people with unique ego could adapt to adverse events and protect themselves from being depressed ${ }^{[16]}$. The previous studies have demonstrated that CSE has a significant correlation with depression. Compared to the individual with low CSE, the individual with high CSE has a lower sense of stress and tension and negative emotions, for example, sense of anxiety and depression. Besides, the individual with high CSE can have a higher sense of safety and lower sense of frustration, and therefore believe in himself and finally get a higher self-efficacy ${ }^{[17]}$. However, the low selfrespect (i.e. even more negative attitude to oneself) and low sense of self-efficacy are closely related to depressive disorder, and can be used to predict symptoms of the depressive disorder ${ }^{[18]}$. Based on the above analysis, this paper indicates that SES can affect the level of depression through CSE, i.e. CSE is a mediating variable between SES and depression.

This paper aims to discuss the relationship among SES, CSE and depression. This paper creates a mediating model where CSE is used as a mediating variable between SES and depression. Figure 1 shows the hypothesis model here.



Figure 1 Hypothesis model. CSE is a mediating variable between SES and depression

\section{METHODS}

\subsection{Data source}

This paper uses the data of CGSS (Chinese General Social Survey) in 2017. As the first national, comprehensive, and consecutive large-scale social survey project of China, CGSS contains a large number of information, for example, SES, social support variable, psychological health, and demographic characteristic variable, and aims to collect the data of Chinese and the society regularly and systematically. Therefore, this paper aims to discuss the influence of SES on the depression of the Chinese. (The ethics application for collecting data on human subjects was approved by Renmin University of China's Institutional Review Board.) Among the nationwide 12582 samples, 3501 participants are finally included in this paper after the missing values in the constructed variables are deleted.

\subsection{Variables}

\subsubsection{Dependent variables}

SES is a generalized concept which generally measures economic and social status of an individual or family based on incomes, education, occupation or working experience compared to others with economics and sociology. When analyzing the SES of an individual, some scholars indicated that the income level could reflect the reserve of social resources, for example, medical resources, economic resources, and interpersonal resources ${ }^{[19]}$. This paper measures the SES with individual SES identification, family SES identification and individual class identification. The individual SES identification includes 5 grades, with the top grade " 1 " and the bottom grade " 5 ". The family SES identification also includes 5 grades, with the bottom grade "1" ("far lower than the average level") and the top grade "5" ("far higher than the average level"). The participants answer the question here, "how about your family economic status in local place?". The individual class identification includes 10 grades, with the top grade " 10 " and the bottom grade " 1 ".

\subsubsection{Independent variable}

This paper considers depression as the independent variable and uses the depression scale in self-rating depression scale/depression-anxiety-stress scale (DASS- 
21) created by Lobvibnd and widely used in literature ${ }^{[20]}$. This scale sets 7 questions (e.g. "I am depressed and unhappy", "I feel that the life is meaningless" and "I am not enthusiastic about doing anything") to measure the depression condition of Chinese with a score from " 1 Strongly disagree" to "6-Strongly agree". The higher the score is, the higher the degree of depression of an individual will be.

\subsubsection{Mediating variables}

This paper also uses a mediating variable-CSE(Core Self-evaluation) which was created by Judge and used for measuring the CSE level of an individual(Judge et al., 1997). The domestic scholars Du Jianzheng et al revised the Chinese edition of the scale in 2012 and demonstrated that this scale was applicable to Chinese university students and staff of each industry. Besides, the scale sets 10 questions(e.g. "I am depressed and unhappy", "I doubt myself", and "Generally, I am satisfied with myself") to measure an individual with a score from "1-Completely inconsistent" to "8-Completely consistent". The higher the score is, the higher the CSE level will be.

\subsubsection{Control variables}

This paper uses the demographic characteristic variable as the control variable, including age, gender, martial status, and residential area. According to the VIF test, the VIF value of each variable is far lower than the threshold 10. This indicates that there is not serious multicollinearity among different variables.

\section{STATISTICAL ANALYSES}

In the present study, statistical analyses were conducted using SPSS 24.0. Data processing included the following steps. First, we screened the questionnaires based on the existing scales, determined the corresponding questions of each scale in the CGSS questionnaire, and then eliminated the questionnaires with missing values and "don't know" and "does not meet". Second, calculate the mean of each scale and the Pearson correlation coefficient between the means. Third, we used the PROCESS macro for SPSS (Model 4) to investigate the mediating effect of CSE in the relationship between SES and depression(Hayes, 2013).

\section{RESULT}

The descriptive statistics and Pearson correlation coefficients were presented in Table 1 . The results showed whom scored high levels of SES were more likely to have high levels of CSE and low levels of depression. Besides, depression was negatively associated with CSE. In addition, Education was positively associated with SES and CSE, but was negatively associated with depression.

Table 1. Descriptive statistics

\begin{tabular}{lllll}
\hline & $\mathrm{M} \pm \mathrm{SD}$ & 1 & 2 & 3 \\
\hline $1 . \mathrm{SES}$ & $2.989 \pm$ & 1.000 & & \\
& 0.938 & & & \\
2. Depression & $2.983 \pm$ & $-0.309 * *$ & 1.000 & \\
& 0.533 & & & \\
$3 . \mathrm{CSE}$ & $4.462 \pm$ & $0.336 * *$ & $-0.441^{* *}$ & 1.000 \\
& 0.866 & & & \\
\hline
\end{tabular}

NOTE: **Indicates that the correlation is significant at the significance level of 0.01 (two-tailed)

We used Model 4 of the PROCESS macro to examine this hypothesis. The results were presented in Table 2 . The results of total group showed that SES were positively associated with CSE $(\beta$ Total $=0.296, p<0.001)$, which in turn were negatively associated with depression $(\beta$ Total $=-0.169, p<0.001)$. In addition, the results of biascorrected percentile bootstrap method suggested that the indirect effect of CSE in the relationship between SES and depression was significant (indirect effect Total =$0.068,95 \%$ BootCIs Total $=[-0.078,-0.058])$. The male and female groups were basically consistent with the total group results (indirect effect Male $=-0.061,95 \%$ BootCIs Male $=[-0.075,-0.048]$; indirect effect Female $=-0.074$, $95 \%$ BootCIsFemale $=[-0.088,-0.060])$.

Table 2. Testing the mediation effect of SES on depression via CSE.

\begin{tabular}{|c|c|c|c|c|c|c|c|c|c|}
\hline \multirow[b]{2}{*}{ Variables } & \multicolumn{3}{|c|}{ Model 1 (CSE) } & \multicolumn{3}{|c|}{ Model 2 (depression) } & \multicolumn{3}{|c|}{ Model 3 (depression) } \\
\hline & Total & Male & Female & Total & Male & Female & Total & Male & Female \\
\hline SES & $\begin{array}{l}.296^{* * * *} \\
(.015)\end{array}$ & $\begin{array}{l}.281^{* * * * *} \\
(.022)\end{array}$ & $\begin{array}{l}.309^{* * * *} \\
(.020)\end{array}$ & $\begin{array}{l}-.169 * * * \\
(.009)\end{array}$ & $\begin{array}{l}-.165^{* * * *} \\
(.013)\end{array}$ & $\begin{array}{l}-.172^{* * * *} \\
(.013)\end{array}$ & $\begin{array}{l}.101 * * * \\
(.009)\end{array}$ & $\begin{array}{l}-.103^{* * * *} \\
(.013)\end{array}$ & $\begin{array}{l}.098^{* * * *} \\
(.012)\end{array}$ \\
\hline CSE & & & & & & & $\begin{array}{l}-.229 * * * \\
(.010)\end{array}$ & $\begin{array}{l}-.218^{* * * *} \\
(.014)\end{array}$ & $\begin{array}{l}-.238^{* * * *} \\
(.014)\end{array}$ \\
\hline Age & $\begin{array}{l}-.007 * * * \\
(.001)\end{array}$ & $\begin{array}{l}-.006^{* * * *} \\
(.001)\end{array}$ & $\begin{array}{l}-.008 * * * \\
(.001)\end{array}$ & $\begin{array}{l}.002 * * * \\
(.001)\end{array}$ & $\begin{array}{l}.001 \\
(.001)\end{array}$ & $\begin{array}{l}.003 * * * \\
(.001)\end{array}$ & $\begin{array}{l}.000 \\
(.001)\end{array}$ & $\begin{array}{l}.000 \\
(.001)\end{array}$ & $\begin{array}{l}.001 \\
(.001)\end{array}$ \\
\hline Gender & $\begin{array}{l}-.124 * * * \\
(.027)\end{array}$ & & & $\begin{array}{l}.045^{* *} \\
(.017)\end{array}$ & & & $\begin{array}{l}.017 \\
(.016)\end{array}$ & & \\
\hline
\end{tabular}




\begin{tabular}{|c|c|c|c|c|c|c|c|c|c|}
\hline Marital status & $\begin{array}{l}-.009 \\
(.011)\end{array}$ & $\begin{array}{l}.007 \\
(.017)\end{array}$ & $\begin{array}{l}-.017 \\
(.014)\end{array}$ & $\begin{array}{l}.016^{*} \\
(.007)\end{array}$ & $\begin{array}{l}.018 \\
(.011)\end{array}$ & $\begin{array}{l}.013 \\
(.009)\end{array}$ & $\begin{array}{l}.014^{*} \\
(.006)\end{array}$ & $\begin{array}{l}.020 \\
(.010)\end{array}$ & $\begin{array}{l}.009 \\
(.008)\end{array}$ \\
\hline R2 & .141 & .115 & .162 & .109 & .101 & .116 & .228 & .212 & .241 \\
\hline $\mathrm{F}$ & $114.508 * * *$ & $52.353 * * *$ & $90.752 * * *$ & $85.611 * * *$ & $45.141 * * *$ & $61.663 * * *$ & 171.632 & $86.665^{* * * *}$ & $119.352 * * *$ \\
\hline
\end{tabular}

\section{CONCLUSION}

The positive effect of SES on depression has gained increasing empirical support. However, the mediating and moderating mechanisms underlying this association remain largely unexplored. We used CGSS 2017 dataset for empirical analysis. The results show that SES is significantly related to the depression of the Chinese. CSE is a mediating variable between SES and depression. This study provided evidence to further develop our understanding of the conditional indirect effect by which SES influences depression in life, confirmed the applicability of CSE in the intermediate mechanism of the relationship between SES and depression. Therefore, in the study of depression, it is crucial to distinguish the social and family roles of men and women in combination with the actual situation of Chinese society for a more accurate conclusion analysis.

The present study is not without limitations that should be taken into account in further research. First, it is difficult for the cross-section design here to indicate the causal relationship between SES and depression. Second, it may be more complex for the relationship among SES, CSE, level of education, and depression if other factors (e.g. employment, other economic incomes, social security) are considered. Other factors shall be further discussed in the future.

\section{AUTHORS' CONTRIBUTIONS}

Yujie Zhang: Writing-review \& editing. Simeng Dong: Data curation, Writing-review \& editing. Qinnan Dong: Conceptualization, Data curation, Formal analysis, Writing-original draft, Conceptualization, Methodology, Supervision.

\section{ACKNOWLEDGMENTS}

The authors would like to acknowledge the Chinese General Social Survey (CGSS) team for providing data.

\section{REFERENCES}

[1] Case, S. M., Sawhney, M., \& Stewart, J. C. (2017). Atypical depression and double depression predict new-onset cardiovascular disease in u.s. adults. Depression \& Anxiety. DOI:10.1002/da.22666

[2] Lu, J., Zhang, C., Xue, Y., Mao, D., \& Wang, X. (2019). Moderating effect of social support on depression and health promoting lifestyle for chinese empty nesters: a cross-sectional study. Journal of Affective Disorders, 256. DOI:10.1016/j.jad.2019.04.003

[3] Choi, H., Burgard, S., Elo, I. T., \& Heisler, M., et al. (2015). Are older adults living in more equal counties healthier than older adults living in more unequal counties? a propensity score matching approach. Social Science \& Medicine, 141, 82-90. DOI: $10.1016 /$ j.socscimed.2015.07.020

[4] Ingles, J., Johnson, R., Sarina, T., Yeates, L., Burns, C., \& Gray, B., et al. (2015). Social determinants of health in the setting of hypertrophic cardiomyopathy. International Journal of Cardiology,184, 743-749. DOI: 10.1016/j.ijcard.2015.03.070

[5] Galobardes, B., Shaw, M., Lawlor, D., Smith, G. D., \& Lynch, J. (2006). Indicators of socioeconomic position: methods in social epidemiology. Journal of Epidemiology and Community Health, 60, 47-85. DOI:10.1136/jech.2004.028092

[6] Glymour, M. M., Defries, T. B., Kawachi, I., \& Avendano, M. (2008). Spousal smoking and incidence of first stroke: the health and retirement study. American Journal of Preventive Medicine, 35(3), 245-248. DOI: 10.1016/j.amepre.2008.05.024

[7] Dohrenwend, B., P., Levav, \& I. (1992). Socioeconomic status and psychiatric disorders: the causation-selection issue. Science, 255(5047), 946952.

DOI:10.1126/science.1546291

[8] Johnson, J. G., Cohen, P., Dohrenwend, B. P., Link, B. G., \& Brook, J. S. (1999). A longitudinal investigation of social causation and social selection processes involved in the association between socioeconomic status and psychiatric disorders. J Abnorm Psychol, 108(3), 490-499. DOI:10.1037/0021-843X.108.3.490

[9] Lopez Am, C., Ezzati, M., Jamison, D., Murray, C., Lopez, A., \& Mathers, C., et al. (2008). Global burden of disease and risk factors. Washington D, 22(3), 277-283. DOI:10.1007/BF00404487

[10] Silva, D., Segheto, W., Coelho, F. A., Reis, V. G., Morais, S., Pessoa, M. C., \& Longo, G. Z. (2017). 
Risk and protective factors for chronic diseases in adults: a population-based study. Ciencia \& saude coletiva, 22(12), 4041-4050. DOI:10.1590/1413812320172212.07862016

[11] Judge, T. A., Erez, A., Bono, J. E., \& Thoresen, C. J. (2002). Are measures of self-esteem, neuroticism, locus of control, and generalized self-efficacy indicators of a common core construct?. Journal of Personality and Social Psychology, 83(3), 693-710. DOI:10.1037/0022-3514.83.3.693

[12] Kraus, M. W., Piff, P. K., Mendoza-Denton, R., Rheinschmidt, M. L., \& Keltner, D. (2012). Social class, solipsism, and contextualism: how the rich are different from the poor. Psychological Review, 119(3), 546. doi:10.1037/a0028756

[13] Hsieh, H., \& Huang, J. (2014). The effects of socioeconomic status and proactive personality on career decision self-efficacy. The Career Development Quarterly, 62(1). DOI: 10.1002/j.2161-0045.2014.00068.x

[14] Virginie, Wiederkehr, Céline, Darnon, Sébastien, \& Chazal, et al. (2015). From social class to selfefficacy: internalization of low social status pupils' school performance. Social Psychology of Education. DOI:10.1007/s11218-015-9308-8

[15] Yerdelen-Damar, S., \& Pe?Man, H. . (2013). Relations of gender and socioeconomic status to physics through metacognition and selfefficacy. Journal of Educational Research, 106(4), 280-289. DOI:10.1080/00220671.2012.692729

[16] Linville, \& Patricia, W. (1987). Self-complexity as a cognitive buffer against stress-related illness and depression. Journal of Personality \& Social Psychology, 52(4), 663-676. DOI:10.1037/00223514.52.4.663

[17] Jiang, \& Zhou. (2015). Core self-evaluation and career decision self-efficacy: a mediation model of value orientations. Personality \& Individual Differences, 86, 450-454.

DOI: 10.1016/j.paid.2015.07.012

[18] Ernestus, S. M., Prelow, H. M., Ramrattan, M. E., \& Wilson, S. A. . (2014). Self-system processes as a mediator of school connectedness and depressive symptomatology in african american and european american adolescents. School Mental Health, 6(3), 175-183. DOI:10.1007/s12310-014-9122-Z

[19] Smith, J., \& Kington, R. (1997). Demographic and economic correlates of health in old age. Demography, 34. DOI:10.2307/2061665
[20] Lovibond, P. F., \& Lovibond, S. H. (1995). The structure of negative emotional states: Comparison of the Depression Anxiety Stress Scales (DASS) with the Beck Depression and Anxiety Inventories. Behaviour research and therapy, 33(3), 335-343. DOI: 10.1016/0005-7967(94)00075-U 